\section{Training of Surgeons}

Sir,--You recently allowed me to state some of my views on the training of surgeons (9 November, p. 379). The reaction in your correspondence columns, and more so privately to me, has been very much in agreement with my comments and proposals, and a terminal paragraph, "unfortunately nothing is likely to be done," was almost as standard an ending to the letter as "Yours sincerely."

Your leading article on the subject (16 November, p. 401) bore little on the main points of my thesis-the necessity to give the trainee surgeon a fair deal-and was more a statement of pious intent on higher specialist training and certification, regrettably lacking in any sense of urgency and drive to get it implemented. This aspect of the training is important, but it is the basic structure of the training which needs organizing and riveting into a stable, functioning entity, and it requires definitive and detailed planning.

The decision, therefore, of the Royal College of Physicians and Surgeons of Glasgow to make radical changes in the primary fellowship examination (22 February, p. 502) is more than welcome. Their institution of a basic sciences examination to replace the primary F.R.C.S., and perhaps part one M.R.C.P. examination and part one of the M.R.C.O.G. examination, is well along the lines which I advocated of a common basic sciences examination two years after qualification for candidates for all branches of consultant training - anaesthetics, pathology, radiology, psychiatry, etc.- -and it is to be hoped tha the inevitable success of their innovation will lead to its adoption throughout the royal col leges. It could be the first step towards the correction of the present anomaly of unequal status of the fellowship diplomas of the surgical royal colleges. Above all it is good to have some concrete evidence that something practical is being donc somewhere about the training requirements.

In comments on my article some doubt was expressed on the necessity for this country to undertake the postgraduate training of overseas doctors. In this view I cannot share. Even though we should aim at a complete reorganization of the National Health Service staffing of hospitals as advocated by $\mathrm{Mr}$. John Charnley (7 December, p. 643), with whom I fully agree, that cannot happen overnight, and we must have the overseas gradu ates to staff our hospitals for some time to come. Apart from this, however, it is a basic tenet of our profession that we should pass on our knowledge, and that men should wish to come here to learn from us should be a source of immense satisfaction and a proud stimulus to maintain our standards. If we can provide these men with work to do the experience is immeasurably more valuable. The statements in your leading article (16 November, p. 401), "All registrar and senior registrar posts should now be regarded as training posts in which training must take priority over service, and not vice versa," and "senior registrar appointments should be supernumerary to service requirements," are woefully wide of the mark indeed, and such ideas must be eradicated if training is to be vitalized.

The essential points in training requirements cannot be stated too often at this time. Some body, preferably the royal colleges, should assume responsibility for a detailed training schedule for trainees. The progres of each trainee should be carefully supervised. There must be an organization responsible for arranging training facilities in this country for graduates referred by their universities abroad for postgraduate specialist training. Trainees not destined to achieve final consultant status must be aware of this early in their careers, and must not be rejected after years of training. The examinations must be more equitably related to training and the standard of competence which the candidate can be expected to achieve before being eligible for the examination. Men who have completed their training must be able to move into posts of responsibility without delay.

Above all, let us get the programme moving.-I am, etc.,

\section{Whittington Hospital,
London N.19.}

Neville Stidolph.

\section{Swimming in Cold Water}

SIR,-I first heard of the work of Dr. W $R$. Keatinge and his colleagues on experimental hypothermia (22 February, p. 480) at a Society of Occupational Medicine meeting in 1967, and realized the implications and bearing which this work might have on the personal survival award scheme promoted by the Amateur Swimming Association.

In this scheme swimmers, most of them young children, are taught and trained in the art of swimming with their clothes on; disrobing in the water; inflating their garments to make a float ; and finally, having shed their clothing, swimming 1,000 yards $(914 \mathrm{~m}$.), during which there is some underwater negotiation of obstacles.

This scheme, admirable though it is as a test of endurance, as its name implies, forms the basis of the techniques which these children might follow if ever they found themselves in the unfortunate position of being irretrievably overboard. It occuirred to me that this was a dangerous illusion to instil into the minds of these children, and that there was a risk that lives may be lost from hypothermia by both undressing and the subsequent physical effort of swimming in the cold water.

I approached the Amateur Swimming Association with these views and informed them of the work of Dr. Keatinge and his colleagues at the M.R.C. body temperature research unit at Oxford. I am now pleased to report that information regarding hypothermia is to be passed on to the swimmers taking survival awards; emphasis is to be placed on the subject in the literature and also in a film which is to be made for teaching purposes.-I am, etc.,

\section{S. SHEFFRIN}

Honorary Medical Adviser Yorkshire Amateur Swimming Association. Leeds,
Yorks.

SIR,-As an active member of an open-air, all-the-year-round swimming club I was interested to read of this recent experiment (22 February, p. 480) and hope that one or two observations and criticisms may be acceptable.

First, it is contended that the element of apprehension was largely removed from the experimental situation. Whether or not this was the case depends much on the degree to which the participants were conditioned, both in relation to the clothing and apparatus worn and, more especially, to their cold water immersion. It is not uncommon for our newer members to experience similar difficulty in controlling and co-ordinating breathing with swimming movements, even if this was previously not difficult in warm water, when they first attempt winter bathing. Certainly, if they had had difficulty with this at summer temperatures, their troubles are much magnified in winter, and this happens whether they are well covered or leanly built. On the other hand, we have among our regular customers at least six really thin specimens, and none of them experience any difficulty whatever in controlling this reflex, with the result that they are not in the least troubled by incoordinate breathing at any stage. I have myself noticed after finishing a hundred yards' $(91 \mathrm{~m}$.) dash in the water that I have to slow down for some twenty cycles before I can continue my journey. During this period I experience acute dyspnoea, which eases off quite rapidly without my having to break the rhythm of the stroke, and I am able to resume at a new and faster pace again. I would suggest this reflex overbreathing is largely the product of circumstance and temperament, that it is readily engendered by apprehension-as the writers suggestbut that it is also easily controlled by voluntary effort once this has been learnt, and that the amount of body fat is not relevant.

With regard to hypothermia, I am convinced that this is still the more dangerous hazard, mainly because of the speed with which it seems to act, especially at near-zero temperatures. I suspect that while the panic situation in an accident rapidly prevents effective swimming, this is less due to hyperventilation per se than to impaired cerebral function rapidly supervening in an environment when conservation of energy should be the most important aim. Many people, practised swimmers included, fail to recognize that the work required to swim fully clothed is very much greater than that needed when wearing trunks. I think it is also worth emphasizing the extent to which postimmersion cooling persists, and the only remedy for this is a hot bath-not just a five-minute dip in warm water.-I am, etc.,

\section{Medical Department,
Greater London Council County $H$ ond London S.E.1.}

\section{J. WOOLDRIDGE.}

\section{Swimming and Phenothiazines}

SIR,-In their article "Sudden Failure of Swimming in Cold Water" (22 February, p. 480) Dr. W. R. Keatinge and others warn of the danger of respiratory distress and hypothermia during swimming. I would like to draw attention to a similar danger of swimming in less extreme conditions in patients who are taking phenothiazine drugs. This group of substances are known to exert an effect upon the hypothalamus and to be capable of inducing hypothermia through interference with the central temperatureregulating mechanisms. ${ }^{1}$

It is not uncommon in psychiatric hospitals to include swimming in social recreation programmes for patients. Some years ago convalescent schizophrenic patient under my 
care, who was taking $300 \mathrm{mg}$. per day of chlorpromazine, collapsed in a hypothermic state while swimming in a public swimmingbath. Rewarming and resuscitation produced complete recovery.

The possible hazard of hypothermia and respiratory distress due to swimming in patients taking phenothiazine drugs is not generally recognized, and would merit further laboratory and clinical investigation.-I am, etc.,

JOHN JOHNSON.

REFERENCE

1 Shepherd, M., Lader, M., and Rodnight, R.,

Clinical Psychopharmacology, 1968
Universities Press Ltd., London.

\section{Anticoagulants in Acute Myocardial Infarction}

SIR,-It was good to see the complete vindication of short-term anticoagulant therapy after cardiac infarction provided by the findings of the M.R.C. Working Party (8 February, p. 335). However, the summary, if read in isolation, might tend to confirm the nihilist in his views. There seems to be undue emphasis on the minimal difference found between the overall mortality rates in the two groups. The statement that this difference "could have occurred by chance" is, of course, statistically true, but, on the evidence of the published findings, clinically misleading.

Reinfarction occurred more commonly in the low-dosage group (Table XIV). The difference between the two groups did not reach " technical levels of significance," but there is only a $6 \%$ likelihood (corresponding approximately to the $\chi^{2}$ value of 3.575 ) that this observed difference was a chance finding. From the clinical standpoint these very substantial odds that such evidently safe therapy may avert some reinfarction episodes and their consequences surely justify its use from the outset. The differing pattern of reinfarction in relation to time in the two groups is mentioned in the text, though the highly significant degree of this difference is not pointed out $\left(\chi^{2}\right.$ with correction factor $=7 \cdot 7$, $\mathrm{p}<0.01)$, nor the fact that the trend reversal in favour of the low dosage group after the first week is confined to females.

The significant reduction in thromboembolic complications in the "high-dosage" group is recognized in the text. While in itself a justification of therapy, this finding and the above reinfarction differences make one wonder why the low-dosage group of patients did not show a clear-cut increase in mortality. The answer to this apparent paradox may lie in the subsequent clinical management of patients in this group who suffered such complications. In 67 cases "high-dosage" anticoagulant therapy was instituted following reinfarction or other thromboembolic incident (Table XIX), presumably because the physician considered it potentially beneficial. However, the final results in these cases were analysed with the remainder of the lowdosage grcup. This would have been justifiable only if "high-dosage" therapy were known to have no influence on the results, and, of course, the trial was instituted to provide evidence on this very point. If " highdosage" therapy has indeed a beneficial effect the mortality rate in the low-dosage group will thus have been artificially lowered and any real difference between the two groups will have been masked.

The highly significant reduction in morbidity due to systemic artery occlusion, leg vein thrombosis, and pulmonary embolism will presumably make further trials of this nature ethically unjustifiable. It would therefore be interesting to know the times of occurrence of the thromboembolic complications and also the time of death in those found to have thromboembolism at necropsy. We found ${ }^{1}$ that all the thromboembolic episodes in patients with heart failure and on phenindione occurred within the first 10 days of the drug's administration. By contrast, such episodes in the control group occurred between 7 and 44 days after zero time (day of admission). We concluded that this difference might have been due to some thrombogenic tendency of the oral anticoagulant during the early days of its administration-that is, before "therapeutic" prothrombin levels had been attained. There is some experimental evidence to support this concept. $^{2}$ Intermittent heparin therapy during the first 36 hours, as given in the trial, is unlikely to provide adequate protection against any such effect.-We are, etc.,

Addenbrooke's Hospital,
Cambridge.
Geigy (U.K.) Ltd., W. Evans.
Macclesfield, Cheshire.
Refrerences
Domenet, J. G., Evans. D. W., and Stephenson,
H., Brit. med. F., 1966, 2, 866.
Merskey, C., and Drapkin, A., Blood, 1965, 25,
Merskey, C., and Drapkin, A., Blood, 1965, 25,
567.

SIR,-Dr. L. Poller (1 March, p. 572) has unerringly pinpointed the weakness in the M.R.C. report on anticoagulant treatment for acute myocardial infarction (8 February, p. 335), and this should do much towards redressing the balance that its "weighty" conclusions appear to tilt against this form of therapy. As in some former trials, once more it can fairly be said that the bad results of anticoagulant treatment in this condition are the results of bad anticoagulant treatment; and it can still be shown that this therapy is meat for humans with coronary artery disease, even if it is also (in the words of a world-famous cardiologist) poison for rats.-I am, etc.,

\section{Department of General Medicine, Glam.
Glamorgan General Hospital \\ Treatment of Hypertension with Propranolol}

SIR,-The paper by Drs. B. N. C. Prichard and P. M. S. Gillam (4 January, p. 7) was of particular interest, containing as it did an extension to propranolol of the excellent comparative study of bethanidine, guanethidine, and methyldopa in hypertension, ${ }^{1}$ as well as a general review of the place of propranolol in hypertensive therapy.

It is true that a number of papers in the last few years have not shown propranolol to have any consistent hypotensive effect. How- ever, the value of much of the work done has in my view been reduced by three factors: (1) The comparatively small numbers involved; (2) the comparatively short duration of the trials ; (3) the arbitrary (and not necessarily optimum) dosage of propranolol used. The situation might be clarified by a double blind trial in which the participants had already been taking a dose of propranolol known to be appropriate for their needs. Clearly this can only be done in a department where the drug has been studied for some time and where a prima facie case for its value in hypertension has been established.

I have been engaged on a detailed study of propranolol for nearly five years, involving 240 patients, with a smaller percentage of failures than with any other drug used in the past 15 years, and, having carefully studied the comments of Drs. Prichard and Gillam on the side-effects of propranolol and its general acceptability to patients, I feel bound to agree with them completely and to endorse their conclusions. Drs. G. S. Humphries and D. G. Delvin (15 February, p. 445) remain sceptical, but in my experience the doses which they used are by no means adequate for a large percentage of hypertensive patients. In my department we have been conducting for the past five months a double blind trial in which all participating patients have already been adequately controlled by propranolol, many of them for a year or more, and when completed this trial will have lasted eight months.-I am, etc.,

\section{F. J. Zacharias.}

Hypertension Unit, Clatterbridge Hospital
Wirral, Cheshire. REFERENCE

1 Prichard B. N. C., Johnston, A. W., Hill, I. D $\mathrm{D}^{\text {, }}$ 135 .

\section{Progestogen is not Progesterone}

SIR,-It is unfortunate and misleading that Dr. L. Poller and his colleagues (1 March, p. 554) should use the term progesterone in their valuable paper reporting studies on blood coagulation in women using continuous low dosage progestogen for oral contraception. Although this term occurs several times in the paper, not once does it refer to $\Delta_{4}$-pregnene-3,20-dione, the only compound properly called progesterone. The compound studied, chlormadinone $\left(\Delta_{r}-6\right.$ chloro-17 $\alpha$-acetoxyprogesterone) is, of course, not progesterone, and neither has any formulation hitherto used for contraceptive purposes ever contained progesterone.

It seems a pity that the important finding reported by the authors-that, within the limits of their trial, chlormadinone, unlike oestrogen-containing oral contraceptives, does not appear to cause increased coagulability or platelet aggregation-should be vitiated by terminological misuse producing such inaccurate and unwarranted statements as, for example, the one on which the article concludes: ". . . the investigation does suggest that the thrombogenic constituent of conventional oral contraception may have been eliminated by the use of progesterone alone." Of course, it does nothing of the kind. -I am, etc.,

London N.W.1. 